\title{
Conceptualizing Usability for the eHealth Context: Content Analysis of Usability Problems of eHealth Applications
}

Marijke Broekhuis ${ }^{1,2}$, MSc; Lex van Velsen ${ }^{1,2}, \mathrm{PhD}$; Linda Peute ${ }^{3}, \mathrm{PhD}$; Meilani Halim ${ }^{4}, \mathrm{BSc}$; Hermie Hermens ${ }^{1,2}$, Prof Dr, IR

${ }_{1}^{1}$ Roessingh Research and Development, Enschede, Netherlands

${ }^{2}$ Biomedical Signals and Systems, Faculty of Electrical Engineering, Mathematics and Computer Science (EEMCS), University of Twente, Enschede, Netherlands

${ }^{3}$ Center for Human Factor Engineering of Health Information technology, Department of Medical Informatics, Amsterdam UMC, University of Amsterdam, Amsterdam, Netherlands

${ }^{4}$ Communication Sciences, Faculty of Behavioural, Management and Social Sciences (BMS), University of Twente, Enschede, Netherlands

\section{Corresponding Author:}

Marijke Broekhuis, MSc

Roessingh Research and Development

Roessinghsbleekweg 33b

Enschede, $7522 \mathrm{AH}$

Netherlands

Phone: 310880875728

Email: m.broekhuis@rrd.nl

\section{Abstract}

Background: Usability tests can be either formative (where the aim is to detect usability problems) or summative (where the aim is to benchmark usability). There are ample formative methods that consider user characteristics and contexts (ie, cognitive walkthroughs, interviews, and verbal protocols). This is especially valuable for eHealth applications, as health conditions can influence user-system interactions. However, most summative usability tests do not consider eHealth-specific factors that could potentially affect the usability of a system. One of the reasons for this is the lack of fine-grained frameworks or models of usability factors that are unique to the eHealth domain.

Objective: In this study, we aim to develop an ontology of usability problems, specifically for eHealth applications, with patients as primary end users.

Methods: We analyzed 8 data sets containing the results of 8 formative usability tests for eHealth applications. These data sets contained 400 usability problems that could be used for analysis. Both inductive and deductive coding were used to create an ontology from 6 data sets, and 2 data sets were used to validate the framework by assessing the intercoder agreement.

Results: We identified 8 main categories of usability factors, including basic system performance, task-technology fit, accessibility, interface design, navigation and structure, information and terminology, guidance and support, and satisfaction. These 8 categories contained a total of 21 factors: 14 general usability factors and 7 eHealth-specific factors. Cohen $\kappa$ was calculated for 2 data sets on both the category and factor levels, and all Cohen $\kappa$ values were between 0.62 and 0.67 , which is acceptable. Descriptive analysis revealed that approximately $69.5 \%$ (278/400) of the usability problems can be considered as general usability factors and $30.5 \%(122 / 400)$ as eHealth-specific usability factors.

Conclusions: Our ontology provides a detailed overview of the usability factors for eHealth applications. Current usability benchmarking instruments include only a subset of the factors that emerged from our study and are therefore not fully suited for summative evaluations of eHealth applications. Our findings support the development of new usability benchmarking tools for the eHealth domain.

(JMIR Form Res 2021;5(7):e18198) doi: 10.2196/18198

\section{KEYWORDS}

usability benchmarking; eHealth systems; content analysis; usability framework; summative evaluation; mobile phone 


\section{Introduction}

\section{Background}

Usability tests of eHealth applications can be either formative (where the aim is to detect usability problems) or summative (where the aim is to benchmark usability). Formative usability tests use qualitative methods, think aloud protocols [1,2], interviews [3], cognitive walkthrough [4], heuristic evaluation [5], or quantitative methods, such as user task performance [6]. Formative tests are mainly used to track usability problems, which are crucial for optimizing a system. However, they do not provide an absolute score of a system's usability. Instead, this can be achieved via usability benchmarking methods during summative evaluations. A usability benchmark is a clear indicator of when the usability of an eHealth application is considered sufficient or insufficient. Furthermore, benchmarking makes it easy to compare the usability of an eHealth application with that of competitors, or to compare scores of new and old versions of the same system to determine whether usability has dropped, improved, or stayed the same. Benchmarking the usability of an eHealth application is most frequently done using questionnaires [7], such as the Poststudy System Usability Questionnaire (PSSUQ) [8], the questionnaire for user interface satisfaction [9], and the system usability scale (SUS) [10]. In addition, there are dedicated eHealth-specific usability benchmarking instruments, such as the Health Information Technology Usability Evaluation Scale (Health-ITUES) [11] and the Mental Health App Usability Questionnaire (MAUQ) [12]. The SUS is currently the most popular usability benchmarking tool for eHealth applications [13]. However, a recent examination of the suitability of the SUS to the eHealth context found that this instrument was not sufficient [14]. All of these questionnaires provide a verdict on usability based on the outcomes of the average scores of user-rated items. Each of these items is related to overarching factors that make up the construct of usability. Traditionally, usability is broken down into three factors: effectiveness, efficiency, and satisfaction [15]. However, each questionnaire proposes a different set of factors and thus, provides a different interpretation of usability. For example, the PSSUQ assesses usefulness, information quality, and interface quality, whereas the Health-ITUES measures the quality of work life, perceived usefulness, ease of use, and user control. Finally, the SUS has no constructs, only items that result in a single score for overall usability without defining what this score means. Thus, the proper benchmarking of usability should start by defining which factors make up the usability of a particular type of system [16].

It has been argued that usability should be considered from the perspective of the system domain [17]. eHealth applications are designed to inform about, prevent, diagnose, treat, or monitor health conditions. This requires users to, for example, understand the health information the system offers, need to be able to keep track of their progress, or need to be able to correctly perform exercises or fill out questionnaires based on the information that is available in the system. These activities can be complicated if patients have low health literacy [18] or if there are health impairments that are common for the intended patient group, which could hinder user-system interaction $[19,20]$.
Furthermore, eHealth applications that are designed for a large audience, such as preventative healthy aging systems, need to consider an extremely diverse user group in terms of motivation and educational level [21].

The problems with current usability benchmarking tools for the eHealth context stem from a general lack of understanding of usability within the eHealth context [12]-eHealth usability. Many studies that attempt to classify usability factors for eHealth do so via a theoretical reclassification of earlier, traditional models [22-27]. This means that we merely rephrase or recategorize the same factors for eHealth instead of eliciting domain-specific usability factors. In order to gain insights into the factors that make up eHealth usability, we need to go back to the drawing board: analyzing problems end users experience when interacting with eHealth applications. The proper usability of eHealth applications is not just about smooth navigation, clear understanding of used language, or prevention of system errors but also involves the patient's perspective and focuses on understanding how a system supports them in prevention, diagnosis, treatment, or monitoring of their health condition [28-30]. However, chronic illnesses can increase patients' feelings of stress and anxiety [31], which can affect the manner in which they interact with an eHealth application and thus the perceived usability. In contrast, for health professionals, for example, nurses, proper usability could mean an entirely different thing. For them, it is important that the system fits within their daily work routine. The study by Ash [32] describes how digital patient care information systems, while implemented with good intentions to make work easier for health professionals, can have unforeseen negative consequences (eg, additional workload or information overload of overfragmentation of data), making it unusable for the intended user group. A thorough understanding of eHealth usability supports formative evaluation methods that aim to elicit lists of usability problems, as well as supporting benchmarking tools.

\section{Objectives}

By analyzing multiple data sets of usability problems found in contemporary eHealth applications, we propose a conceptualization of usability for the eHealth domain from the patient's perspective. An overview of eHealth-specific usability factors helps usability practitioners to link usability problems to an overarching classification that is tailored to the specific medical context in which these applications are embedded.

\section{Methods}

Data sets of usability tests were collected to conduct a content analysis of usability problems found in eHealth usability tests.

\section{Data Source Collection}

We analyzed 8 data sets from different usability tests conducted at institutions affiliated with the researchers. The data sets were strategically chosen to reflect a wide range of eHealth applications with different end-user groups, devices, and health goals. A data set was included if the eHealth application was recently developed; usability problems were elicited via at least one qualitative data collection method (eg, thinking aloud, 
interviews, and observations); and the participants of the usability tests consisted of patients.

The following eHealth applications were included in this study: (1) Stranded, a web-based gamification application in which users can progress in the game by regularly performing physiotherapeutic exercises that are scheduled by a physiotherapist [14]; (2) a web-based screening module provided by a tablet and a care robot (NAO, a humanoid robot from SoftBanks Robotics), in which older adults completed a frailty test and performed physical exercises [33]; (3) cVitals, a home-monitoring module for patients with chronic obstructive pulmonary disease to monitor their health, which consists of a web application that is connected to a blood pressure monitor and weight scale monitor; (4) Council of Coaches, a web-based multi-agent virtual coaching platform for older adults to support a healthy lifestyle via dialogues, web-based coaching, and exercises from multiple virtual coaches that represent various health dimensions (eg, social and physical and mental health); (5) Pandit, a web application for patients with diabetes that provides insulin dosing advice using a clinical decision support system [34]; (6) Pregnancy and Work application (in Dutch: Zwangerschap en Werk) a mobile app for pregnant women to inform them about the rules and regulations on the work floor with regard to pregnancy; (7) FatSecret, a mobile food diary app for diabetes patients; and (8) Hospitality app, a mobile app that provides valet navigation service for out-clinic patients to heighten hospitality toward patients and facilitate hospital attendance [35].

\section{Usability Problems and Severity}

The data sets had a total of 486 usability problems. We excluded usability problems that had unclear formulation, were duplicated, or were unrelated to usability (eg, user experience and motivation). For example, the problem User presses the home button of the iPad for too long, after which Siri comes up instead of home screen (from data set 3 ) is a problem with the device (tablet) and not with the eHealth application. Another problem, Not willing to watch the video and starts practicing (from data set 2), is a problem with user motivation and not with the eHealth application. In addition, the problem, It took users a long time to find the correct functions (from data set 7) does not specify what functions are difficult to find. Finally, the problem Does not like the music (from data set 1) is not a usability problem but a user experience problem.

A total of 86 usability problems were eliminated from the data set, resulting in 400 usability issues that were suitable for the analyses. Each usability problem was assigned to a severity category. Most data sets included severity ratings based on the severity index of Duh et al [36]. This categorization differentiates among minor, serious, and critical usability problems. A minor usability problem occurs infrequently among the participants or the problem only increases the task completion time slightly. A serious usability problem frequently occurs among the participants or the problem severely increases the task completion time. A critical usability problem occurs when all participants have the same problem or the problem prevents participants from completing tasks. In case a data set consisted of different severity index, this index was transposed to the index of Duh et al [36].

Table 1 presents a complete overview of the characteristics of the eHealth applications, the end-user group, and the evaluation method per system. 
Table 1. Overview of data sets $(\mathrm{N}=8)$.

\begin{tabular}{|c|c|c|c|c|c|c|c|c|c|}
\hline $\begin{array}{l}\text { Data } \\
\text { set }\end{array}$ & $\begin{array}{l}\text { eHealth appli- } \\
\text { cation }\end{array}$ & $\begin{array}{l}\text { Description of } \\
\text { app }\end{array}$ & Main health goal & $\begin{array}{l}\text { Device plat- } \\
\text { form }\end{array}$ & $\begin{array}{l}\text { Target end- } \\
\text { user group }\end{array}$ & $\begin{array}{l}\text { Participants, } \\
\mathrm{n}\end{array}$ & $\begin{array}{l}\text { Evaluation } \\
\text { method }\end{array}$ & $\begin{array}{l}\text { Length of } \\
\text { session } \\
\text { (minutes) }\end{array}$ & $\begin{array}{l}\text { Usability } \\
\text { problems, } \\
\text { n }\end{array}$ \\
\hline 1 & Stranded & $\begin{array}{l}\text { Web-based gami- } \\
\text { fied app }\end{array}$ & $\begin{array}{l}\text { Offers fall preven- } \\
\text { tion training via } \\
\text { video instructions } \\
\text { in a gamified en- } \\
\text { vironment }\end{array}$ & Computer & $\begin{array}{l}\text { Prefrail }^{\mathrm{a}} \\
\text { and frail } \\
\text { older } \\
\text { adults } \\
\text { (aged } \geq 65 \\
\text { years) }\end{array}$ & 19 & $\begin{array}{l}\text { Concurrent } \\
\text { think aloud } \\
\text { and screen } \\
\text { capture } \\
\text { recordings }\end{array}$ & 60 & 66 \\
\hline 2 & $\mathrm{~N} / \mathrm{A}^{\mathrm{b}}$ & $\begin{array}{l}\text { Web-based } \\
\text { screening module }\end{array}$ & $\begin{array}{l}\text { Identifies frailty } \\
\text { levels among old- } \\
\text { er adults and sup- } \\
\text { ports physical ex- } \\
\text { ercising }\end{array}$ & $\begin{array}{l}\text { Tablet and } \\
\text { social robot }\end{array}$ & $\begin{array}{l}\text { Prefrail } \\
\text { and frail } \\
\text { older } \\
\text { adults } \\
\text { (aged } \geq 70 \\
\text { years) }\end{array}$ & 20 & $\begin{array}{l}\text { Video observa- } \\
\text { tion }\end{array}$ & 50 & 64 \\
\hline 3 & cVitals & $\begin{array}{l}\text { Home-monitor- } \\
\text { ing tool }\end{array}$ & $\begin{array}{l}\text { Allows self-man- } \\
\text { agement of health } \\
\text { by providing and } \\
\text { supporting health } \\
\text { measurements at } \\
\text { home }\end{array}$ & Smartphone & $\begin{array}{l}\text { Patients } \\
\text { with heart } \\
\text { failure or } \\
\text { COPD }^{c} \\
\text { (aged } \geq 65 \\
\text { years) }\end{array}$ & 10 & $\begin{array}{l}\text { Concurrent } \\
\text { think aloud } \\
\text { and observa- } \\
\text { tions }\end{array}$ & 60 & 39 \\
\hline 4 & $\begin{array}{l}\text { Council of } \\
\text { Coaches }\end{array}$ & $\begin{array}{l}\text { Web-based } \\
\text { coaching plat- } \\
\text { form with virtual } \\
\text { coaches }\end{array}$ & $\begin{array}{l}\text { Supports a } \\
\text { healthy lifestyle } \\
\text { for older adults }\end{array}$ & Computer & $\begin{array}{l}\text { Older } \\
\text { adults } \\
\text { (aged } \geq 55 \\
\text { years) }\end{array}$ & 18 & $\begin{array}{l}\text { Think aloud } \\
\text { and observa- } \\
\text { tions }\end{array}$ & 60 & 60 \\
\hline 5 & Pandit & $\begin{array}{l}\text { Web-based appli- } \\
\text { cation }\end{array}$ & $\begin{array}{l}\text { Allows self-man- } \\
\text { agement of health } \\
\text { by providing in- } \\
\text { sulin dosing ad- } \\
\text { vice }\end{array}$ & Computer & $\begin{array}{l}\text { Patients } \\
\text { with type } 2 \\
\text { diabetes } \\
\text { (aged 40- } \\
64 \text { years) }\end{array}$ & 5 & $\begin{array}{l}\text { Concurrent } \\
\text { think aloud } \\
\text { and observa- } \\
\text { tions }\end{array}$ & 15 & 28 \\
\hline 6 & $\begin{array}{l}\text { Pregnancy and } \\
\text { Work }\end{array}$ & $\begin{array}{l}\text { Informational ap- } \\
\text { plication }\end{array}$ & $\begin{array}{l}\text { Provides informa- } \\
\text { tion on health } \\
\text { risks and regula- } \\
\text { tions during preg- } \\
\text { nancy }\end{array}$ & Smartphone & $\begin{array}{l}\text { Pregnant } \\
\text { women } \\
\text { (aged 25- } \\
40 \text { years) }\end{array}$ & 12 & $\begin{array}{l}\text { Concurrent } \\
\text { think aloud } \\
\text { and observa- } \\
\text { tions }\end{array}$ & 45 & 84 \\
\hline 7 & FatSecret & $\begin{array}{l}\text { Calorie counter } \\
\text { application }\end{array}$ & $\begin{array}{l}\text { Provides nutrition- } \\
\text { al information }\end{array}$ & Smartphone & $\begin{array}{l}\text { Older } \\
\text { adults with } \\
\text { type } 2 \text { dia- } \\
\text { betes (aged } \\
\geq 55 \text { years) }\end{array}$ & 10 & $\begin{array}{l}\text { Concurrent } \\
\text { think aloud } \\
\text { and observa- } \\
\text { tions }\end{array}$ & 15 & 41 \\
\hline 8 & $\begin{array}{l}\text { Hospitality } \\
\text { app }\end{array}$ & $\begin{array}{l}\text { Patient hospitali- } \\
\text { ty app }\end{array}$ & $\begin{array}{l}\text { Provides informa- } \\
\text { tion on how to } \\
\text { prepare for a visit } \\
\text { to medical facili- } \\
\text { ties }\end{array}$ & Smartphone & $\begin{array}{l}\text { Prefrail } \\
\text { and frail } \\
\text { older } \\
\text { adults } \\
\text { (aged } \geq 65 \\
\text { years) }\end{array}$ & 8 & $\begin{array}{l}\text { Concurrent } \\
\text { think aloud } \\
\text { and observa- } \\
\text { tions }\end{array}$ & 30 & 18 \\
\hline
\end{tabular}

${ }^{\text {a }}$ Prefrail refers to the initial state of a health condition called frailty. This condition entails a gradual decline in physical and cognitive functions, mostly occurring among older adults, that can lead to recurrent falls, hospitalization, and even death [37].

${ }^{\mathrm{b}} \mathrm{N} / \mathrm{A}$ : not applicable.

${ }^{\mathrm{c}} \mathrm{COPD}$ : chronic obstructive pulmonary disease.

\section{Data Analysis}

A content analysis was conducted according to the methods of Bengtsson [38], which consists of four stages: decontextualization, recontextualization, categorization, and compilation. Below, we describe the process for each phase. The content analysis was performed by 3 people, all with a background in behavioral sciences, but with different degrees of expertise in coding qualitative data, namely novice $(\mathrm{MH})$, experienced (MB), and expert (LVV).

First, in the decontextualization phase, 2 researchers (MB and $\mathrm{MH}$ ) familiarized themselves with the data sets. Then, they independently started an inductive coding process. Each usability problem was assigned a code that represents the usability factor. On the basis of data sets 1, 2, and 3, each researcher developed their own codebook. These two codebooks 
were discussed and merged in one mutually agreed upon codebook, consisting of 9 main categories and 32 factors. Second, in the recontextualization phase, 2 researchers (MB and $\mathrm{MH}$ ) independently recoded data sets 1-3 using the new codebook. If they found a usability problem that they could not classify using the codebook, a new code was added to the codebook. The resulting codebooks were then compared and discussed, leading to an updated codebook. These steps were performed several times until no new codes emerged. Third, in the categorization phase, definitions for each factor in the updated codebook were formulated, which now consisted of 10 categories and 28 factors. Then, a third independent researcher (LVV) familiarized himself with the data, codebook, and definitions. On the basis of triangular findings, alterations were made to the codebook, resulting in 9 categories and 24 factors. Finally, in the compilation phase, data sets 4, 5, and 6 were independently recoded by two researchers (MB and LVV) using the codebook (deductive coding). Discussions revealed that, although no new categories or factors emerged, there was some overlap in the definitions of some categories and factors that caused confusion about which factor to assign to the usability problem. Therefore, the codebook and definitions were adjusted. The final codebook consisted of 8 categories and 22 factors. The intercoder agreement between researchers MB and LVV was determined by coding data sets 7 and 8 and calculating Cohen $\kappa$ values for both the category and variable levels.

Cohen $\kappa$ is the most widely used means for measuring the intercoder agreement. However, it has its limitations, especially for nondichotomous variables, a measure of relative rather than absolute agreement [39]. One of the main problems with Cohen $\kappa$ is that the higher the number of categories, the less likely there is chance for strong intercoder agreement when using the Cohen $\kappa$ [40]. Therefore, we supplemented Cohen $\kappa$ with a percentage agreement. As a final part of the analysis, we compared the number of minor, serious, and critical usability problems between the usability factors and categories to analyze whether some factors or categories had a significantly higher number of severe usability problems than others.

\section{Results}

\section{Intercoder Agreement}

Validation of the analysis was performed by calculating Cohen $\kappa$ values for both category and factor levels (Table 2 ). The resulting Cohen $\kappa$ values were $\geq 0.62$, both on usability category and factor levels; all percentages were $\geq 66 \%$. These scores can be interpreted as sufficient agreement between the researchers [41].

Table 2. Intercoder agreement expressed as Cohen $\kappa$ and percent agreement for usability categories and factors.

\begin{tabular}{lll}
\hline Data set & Agreement level & Usability factor \\
\hline Data set 8 & Usability category & 18 \\
Usability problems, $\mathrm{n}$ & 18 & 67 \\
Percent agreement (\%) & 72 & 0.63 \\
Cohen $\mathrm{N}$ & 0.62 & 41 \\
Data set 7 & & 66 \\
Usability problems, $\mathrm{n}$ & 41 & 6.62 \\
Percent agreement (\%) & 76 & 0.62 \\
Cohen $\kappa$ & 0.67 & \\
\hline
\end{tabular}

\section{Usability Factors for eHealth Applications}

\section{Overview}

The ontology for usability problems for eHealth applications, which resulted from the coding process, consists of 8 overarching usability categories and 21 factors (Table 3 ). We differentiated between general usability factors (ie, design clarity, interface organization, and navigation) and eHealth-specific usability factors (ie, fit between system and health goals, accommodation to physical limitations, and procedural health-related information). The difference between these 2 types of usability factors (general and eHealth-specific) is that general factors are factors found in eHealth applications that we considered not unique to the eHealth domain (eg, system errors could occur regardless of the type of system), whereas eHealth-specific usability factors are factors related to the medical context in which eHealth applications are embedded (eg, health information, medical terminology, and health goals). 
Table 3. Ontology for usability problems in eHealth applications.

\begin{tabular}{|c|c|}
\hline Category of usability problem and usability factor & Type of usability factor \\
\hline \multicolumn{2}{|l|}{ Basic system performance } \\
\hline Technical performance & General \\
\hline General system interaction & General \\
\hline \multicolumn{2}{|l|}{ Task-technology fit } \\
\hline Fit between system and context of use & General \\
\hline Fit between system and user & General \\
\hline Fit between system and health goals & eHealth-specific \\
\hline \multicolumn{2}{|l|}{ Accessibility } \\
\hline Accommodation to perceptual impairments or limitations & eHealth-specific \\
\hline Accommodation to physical impairments or limitations & eHealth-specific \\
\hline Accommodation to cognitive impairments or limitations & eHealth-specific \\
\hline \multicolumn{2}{|l|}{ Interface design } \\
\hline Design clarity & General \\
\hline Symbols, icons, and buttons & General \\
\hline Interface organization & General \\
\hline Readability of texts & General \\
\hline \multicolumn{2}{|l|}{ Navigation and structure } \\
\hline Navigation & General \\
\hline Structure & General \\
\hline \multicolumn{2}{|l|}{ Information and terminology } \\
\hline System information & General \\
\hline Health-related information & eHealth-specific \\
\hline \multicolumn{2}{|l|}{ Guidance and support } \\
\hline Error management & General \\
\hline Procedural system information & General \\
\hline Procedural health-related information & eHealth-specific \\
\hline \multicolumn{2}{|l|}{ Satisfaction } \\
\hline Satisfaction with system & General \\
\hline Satisfaction with system's ability to support health goals & eHealth-specific \\
\hline
\end{tabular}

\section{Category 1: Basic System Performance}

This category includes usability problems related to the system's technical stability and the user-system interaction. The factor technical performance describes usability problems related to the technical performance of the system, such as system errors, response times, and compatibility with external devices. An example of such a usability problem is the connection with a blood pressure monitor (Omron and Withings) does not work (data set 3, usability problem number 32). The factor general system interaction includes usability problems related to general system interaction elements (eg, use of buttons, scroll bars, swipes, and clicks) and concepts (eg, the types of data entry are inconsistent through the app: String and integer entry, choices, scrolling through dates [data set 7, usability problem number 1]).
Technical problems, such as nonresponsive buttons, can negatively affect efficient system interaction and perceived ease of use. These system errors can seriously hinder task completion and influence users' opinions of other usability aspects. For example, if page load time takes too long (data set 1 , usability problem number 19), a user can also give low ratings to the system's ease of use, navigation, or satisfaction. Good technical performance of the system is essential to facilitate smooth and easy user-system interaction.

\section{Category 2: Task-Technology Fit}

Usability problems found in this category address the match between the system on the one hand, and the user, their context, and health goals, on the other hand. As such, this category is related to the model of Goodhue and Thompson [42], which defines task-technology fit as "the degree to which a technology assists an individual in performing his or her portfolio of tasks." 
The three factors describe usability problems that occur because the eHealth application is not considered suitable because of (1) the daily (clinical) context of use in which the app is to be implemented (eg, participant indicates that she could not print something from the phone easily [data set 6 , usability problem number 86]), (2) the needs of the intended end-user group (eg, the default given for date of birth might not be optimal from the perspective of the average diabetic [data set 7 , usability problem number 3]), and (3) the intended health goals the app is designed to support (eg, the user did not take the system seriously, it was perceived more as a game than as a tool for living more healthily [data set 4, usability problem number 12]). When users perceive a good match between the system and the context, health goals, and themselves, it will lead to not only a more positive impression of the usability of an eHealth application but also a better understanding of its added value.

\section{Category 3: Accessibility}

The category accessibility addresses usability problems that stem from the system's inability to adequately consider or compensate for physical (eg, not able to do the exercise completely due to physical impairments [data set 2, usability problem number 15]), cognitive (eg, the explanation in the support video in the mailbox goes too fast for the user [data set 1, usability problem number 37]), or perceptual (eg, not able to hear NAO due to hearing impairment [data set 2, usability problem number 38]) limitations or impairments that are common to the identified patient groups. These impairments could affect how the user interacts with the system. Problems with moving one's wrist, or having tremors, could make it more difficult to move a mouse and click on objects or buttons. The system could make the buttons larger to make it easier for patients to click on it. Cognitive problems, such as concentration or memory problems, could make a person more forgetful of the things he or she has read. The system can accommodate this by repeating information. To address perceptual problems, for example, bad vision, the system could make the font size larger, so that texts are easier to read.

We were aware that the category accessibility, as the name indicates, is strongly linked to the concept of accessibility $[43,44]$ or related concepts such as universal design [45] and user-sensitive inclusive design [46]. Although it is generally argued that these three concepts are not part of the system usability, previous studies [43-46] have acknowledged that there is a strong link. Our decision to include the category of accessibility hinges on three arguments. First, accessibility, as part of universal access, can promote usability [45]. Second, although accessibility is considered a functional and objective prerequisite for systems, user evaluation of these functionalities remains subjective and from a user perspective, cannot be perceived as separate from the general usability of a system. Third, eHealth applications are often designed for specific patient groups who can have physical, cognitive, or perceptual impairments or limitations. The user-friendly design of such systems therefore inherently provides access to people with such disabilities.

\section{Category 4: Interface Design}

The fourth category, interface design, focuses on the visibility of general user interface (GUI) elements. It has four variables. The first variable, design clarity, includes usability problems related to the size and clarity of a single GUI element (eg, buttons, icons, and graphics). One of the problems we found was that calendar (buttons) was too small, and the user accidentally tapped the field behind the calendar (data set 6 , usability problem number 13). The variable symbols, buttons, or icons covers usability problems about the purpose of the GUI elements in the system. Does the user understand what these are for? For example, it is unclear what it means when the light of the Withings blood pressure monitor blinks (data set 3, usability problem number 1). The third variable, interface organization, concerns the placement and organization of GUI elements on a single screen, for example, the user had problems with the layout of the answering options with a 7 pt Likert scale (data set 4 , usability problem number 3 ). The last variable, readability of texts, describes usability problems related to ease (eg, format, organization, and information density) with which a user can read a text, as well as typographic aspects (eg, font size and line height). For example, information overload in frequently asked question takes a long time to find answers (data set 8 , usability problem number 19 ).

\section{Category 5: Navigation and Structure}

This category describes usability problems related to the simplicity and intuitiveness with which a user can move between different system components and a general understanding of the different system components. The factor navigation relates to the flow between multiple pages and is able to make correct predictions of what can be found in the system. An example of a navigational problem is that navigation with the game is unclear, and the user uses nongaming elements to navigate between the different screens (data set 1, usability problem number 30). Good navigation allows for efficient user-system interaction, that is, it takes less time to complete tasks, and it is easily understood how to perform the tasks [47]. Although system structure is often mentioned as a basic concept that users should be able to understand while using a system [48,49], there is little clarity with regard to the meaning of this concept. In our analysis, the usability factor structure emerged as one that relates to the user's understanding of the system components and the relationships between these different system components. An example of a structural issue is the connection between the beachcomber cabin (for storing stranded items) and the drift bottles (for receiving stranded items) is unclear (data set 1, usability problem number 59). A system structure in which users easily understand how different components relate to each other will positively affect the efficiency and effectiveness with which users can complete system and health-related tasks.

\section{Category 6: Information and Terminology}

This category consists of explanatory, nonaction-related system information and terminology in the app. Usability problems can include issues with understanding labels or terminology, the level of language, or the use of a foreign language. In this category, we made a distinction between system and 
health-related information. The first type includes information about the understandability of explanatory, nonaction-related information and terminology about the system, such as the use of nonnative language (eg, chronic obstructive pulmonary disease questionnaire appears to be in English instead of Dutch [data set 3, usability problem number 35]), whereas the latter includes information related to the understandability of explanatory, nonaction-related information about health, medical terminology, or achieving health goals (eg, patient is not familiar with the word hypoglycemia [does not understand if this means a high or low blood sugar level], but he does understand hypo [data set 5, usability problem number 18]). It is important for eHealth applications that are designed for patients to have medical terminology that is aligned with the patients' vocabulary.

\section{Category 7: Guidance and Support}

The guidance and support category describes usability problems that occur when the system does not provide sufficient support and feedback for tasks that the user has to perform and (potential) errors the user makes. The variable error management refers to the (lack of) feedback mechanisms that are incorporated within the system to prevent user errors. For example, "It was not clear that an incorrect blood sugar level was entered, the error pop-up only explained that there was insufficient information related to the field fasting blood sugar levels" [data set 5, usability problem number 12]. The other two variables in this category covered procedural information. Ummelen [50] describes procedural information as information that is related to conditions for actions, the manner in which actions are to be performed, and results and feedback from these actions. Next, a distinction is made between procedural system information and procedural health-related information. The first describes problems related to system actions (eg, "The system does not explain that the age of the user should be entered numerically, not alphabetically" [data set 4, usability problem number 6]). The second type of procedural information describes problems related to health-related tasks, such as performing physical exercises, filling in food diaries, and completing health questionnaires to measure physiological parameters. For example, it is unclear that the first time is to watch how NAO [a social robot] does the exercise (data set 2, usability problem number 44). These factors, such as error prevention and feedback, are embedded in general usability design principles and heuristics [51]. However, for eHealth applications, these factors are also important to support users in the self-management of their health. For example, being unable to correctly perform physical exercises or not knowing if an exercise has been finished can be detrimental to perceived usability. Users do not know how to successfully complete health tasks and thus, do not know whether and how these tasks contribute to their health.

\section{Category 8: Satisfaction}

This final category concerns the user's satisfaction with the system and addresses the subjective opinion of the user on, or likeability of, an eHealth application. System satisfaction is one of the standard usability variables according to the ISO (International Organization for Standardization) definition [15] and includes usability problems related to the user's satisfaction with the system in general. In addition to this factor, we have identified a second type of satisfaction, namely satisfaction with the system's ability to support health goals. This second variable was added because although the user could believe that the system is nice or fun to use, this does not mean that the system also satisfactorily supports them in their intended health goals. The difference between these two variables is illustrated as follows: the users did not like it when different virtual coaches contradict one another (data set 4 , usability problem number 20). This is a system-satisfaction problem. Some users also mentioned that they did not like the background stories of the virtual coaches (data set 4 , usability problem number 15 ). This is a satisfaction problem related to the potential of the system to support health goals.

\section{Descriptive Analysis}

The eHealth usability ontology includes a total of 21 usability factors, of which 7 are eHealth-specific and 14 are context-independent. Table 4 displays the distribution of 400 usability problems that were included in the analyzed data sets over the different factors. It shows that about $69.5 \%$ (278/400) of the identified issues were of a basic nature and $30.5 \%$ $(122 / 400)$ were health specific. This distribution is also present when we focus on minor, serious, and critical usability problems.

Next, we determined the number of minor, serious, and critical usability problems across the 8 categories (Table 5). The guidance and support category contained the highest number of usability problems, followed by the interface design, basic system performance, and navigation and structure categories. Accessibility and satisfaction had the lowest number of usability problems. Interestingly, although the interface design category has a high number of usability problems, which is $24 \%(96 / 400)$ of the total number of usability problems, only 7 usability problems were marked as critical.

Table 4. Number of basic and health usability problems according to severity category.

\begin{tabular}{llll}
\hline Factor type & Usability problems $(\mathrm{n}=400), \mathrm{n}(\%)$ & \multicolumn{2}{c}{ Severity category, $\mathrm{n}(\%)$} \\
& & Minor $(\mathrm{n}=186)$ & Serious $(\mathrm{n}=147)$ \\
\hline Basic & $278(69.5)$ & $130(69.9)$ & $101(68.7)$ \\
Health & $122(30.5)$ & $56(30.1)$ & $46(70.1)$ \\
\hline
\end{tabular}


Table 5. Number of usability problems of usability categories according to severity level.

\begin{tabular}{lllll}
\hline Usability category & $\begin{array}{l}\text { Severity category } \\
\text { Minor usability problems } \\
(\mathrm{n}=186), \mathrm{n}(\%)\end{array}$ & $\begin{array}{l}\text { Serious usability problems } \\
(\mathrm{n}=147), \mathrm{n}(\%)\end{array}$ & $\begin{array}{l}\text { Critical usability problems } \\
(\mathrm{n}=67), \mathrm{n}(\%)\end{array}$ & $14(20.9)$ \\
\hline Basic system performance & $32(17.2)$ & $10(6.8)$ & $5(7.5)$ & $56(14)$ \\
Task-technology fit & $16(8.6)$ & $7(4.8)$ & $1(1.5)$ & $28(7)$ \\
Accessibility & $2(1.1)$ & $5(3.4)$ & $7(10.4)$ & $8(2)$ \\
Interface design & $51(27.4)$ & $38(25.9)$ & $12(17.9)$ & $96(24)$ \\
Navigation and structure & $12(6.4)$ & $18(12.2)$ & $1(1.5)$ & $42(10.5)$ \\
Information and terminology & $13(6.9)$ & $13(8.8)$ & $25(37.3)$ & $27(6.7)$ \\
Guidance and support & $56(30.1)$ & $55(37.4)$ & $2(3)$ & $136(34)$ \\
Satisfaction & $4(2.1)$ & $1(0.7)$ & $7(1.7)$ \\
\hline
\end{tabular}

\section{Discussion}

\section{Principal Findings}

On the basis of the results of this study, we can reconceptualize the traditional concept of usability in the eHealth context. Our analysis of usability problems in eHealth applications identified 8 main categories for eHealth usability: (1) basic system performance, (2) task-technology fit, (3) accessibility, (4) interface design, (5) navigation and structure, (6) information and terminology, (7) guidance and support, and (8) satisfaction. In each usability category, we made distinctions between factors that were related to general usability (basic usability factors) and those related to the health goals of the system, the medical context, or the characteristics of the intended patient group (health usability factors). We identified 14 general factors and 7 eHealth-specific factors from the analysis. Further examination of the number of usability problems between general and eHealth-specific usability factors revealed that $69.5 \%$ (238/400) of all usability problems were related to general factors and $30.5 \%(122 / 400)$ to eHealth-specific factors. When looking at the severity categories (minor, serious, and critical), we observed the same distribution (70:30) between these two types of factors. This implies that when one applies a general usability benchmarking instrument for evaluating eHealth applications, such as the SUS [10] or the PSSUQ [8], the final score cannot fully cover all usability problems (ie, eHealth-related ones), as eHealth-specific attributes of usability are not taken into account in these instruments. In other words, these general instruments can only explain a maximum of $70 \%$ of the app's usability. To fully assess the usability of eHealth applications, it is necessary to consider these additional eHealth-specific factors.

\section{Comparison With Prior Work}

The finding that the context, be it eGovernment, eCommerce, or eHealth affects usability is, of course, not surprising. Context has been a prominent factor in the definition of usability since the emergence of this construct [52]. However, no studies have yet identified the factors that comprise the usability construct in the eHealth context. In contrast, much research has been conducted to create generic instruments to obtain a rapid and very general assessment of the status of usability of systems, regardless of the system domain or context. Our results showed that the factors related to the medical context influence approximately $30.5 \%(122 / 400)$ of the usability problems that users encounter in eHealth applications, which is a substantial part. Interestingly, several usability evaluation studies of eHealth applications implicitly mentioned how the medical or health context affects the usability of these systems [53-55]. However, these health-related problems are often inadequately categorized under broad concepts, such as usefulness, ease of use, and layout. Our study ties together these findings by providing a fine-grained ontology to which all these health usability problems can be linked. This allows for a better understanding of the usability of eHealth applications. We have provided several examples found in recent literature of why this is necessary.

First, Voncken-Brewster et al [53] found that users, that is, people with a chronic illness, believed that the feedback of the system was not suitable for them because of the progressive physical limitations they experienced. In this study, they classified their usability problems into three main categories: layout, navigation, and content. Although their article did not describe the category under which this problem fell, it feels that none of these three would be a good match. Our ontology provides an alternative option, as this problem can be categorized under accessibility or guidance and support, depending on the specific formulation of the usability problem. Second, Mirkovic et al [54] evaluated the usability of an eHealth application that has two health goals: (1) patient-centered care and (2) self-management of a chronic illness. Their study found that users' evaluation of the usefulness of system modules is based on the need for these modules within their phase of illness. Self-management modules were mostly useful for users who were recently diagnosed. For users who are in a more advanced phase of the illness, patient-doctor communication modules were more important. Although Mirkovic et al [54] categorized this problem as a useful problem, our ontology would suggest the category task-technology fit, as it illustrates how the health goals of a user depend on their phase of illness, which influences the users' opinions on the usability of the evaluated system. Third, Stinson et al [55] found that users had difficulty understanding the labels of the classification of medication types. Although they classified this as a presentation error, our analysis revealed similar problems related to the understanding 
of medical information and terminology. In addition to problems related to the health context, Hattink et al [56] showed that experiencing technical problems is also a major reason for not using systems. Although it seems logical that system errors can affect user friendliness, many benchmarking instruments or heuristics [57,58] do not mention this aspect. In contrast, it was a frequent problem that was identified in our content analysis of usability problems.

With regard to the similarities between, on the one hand, our conceptualization of usability for eHealth and, on the other hand, usability questionnaires, such as the PSSUQ [8], SUS [10], Health-ITUES [11], and MAUQ [12], we observed that each questionnaire measures some of the usability factors we identified in our ontology. For example, the PSSUQ contains items on general system interaction, error management, interface organization, and procedural system information. The SUS contains items on general system interaction, interface organization, and structure. Both of these general usability questionnaires do not consider other general usability factors, such as technical performance, task-technology fit, design clarity, navigation, and health usability factors. eHealth usability benchmarking instruments, such as Health-ITUES and MAUQ, are more suited to measure how an eHealth application can support users in self-managing their health or be applied in a medical context. The Health-ITUES focuses on how the system fits to the daily clinical setting but neglects factors such as navigation, understandability of medical terminology, or interface organization. The MAUQ includes items on how a mobile health app supports users in managing their health and receiving health care or services, in addition to some general usability items such as navigation and interface organization. Each of these four questionnaires covered a handful of the usability factors identified in this study. Our ontology provides a more detailed and thorough overview of the most common usability factors that could hinder the usability of eHealth applications. Therefore, the currently available questionnaires are limited in their predictive value for determining the actual usability of an eHealth application.

\section{Limitations}

This study had two main limitations. First, we intended to include data sets from a wide variety of eHealth application designed for different end-user groups. This was deemed necessary, as we wanted to develop a framework for eHealth applications in general. However, the eHealth applications that we included were, although quite diverse in nature, largely intended for middle-aged or older adults (aged $\geq 40$ years). eHealth applications for other age groups, such as adolescents, could have specific usability problems that are underrepresented in this framework. Future research should determine if these other target groups have other common usability problems that need to be included in the eHealth usability ontology. Second, the Cohen $\kappa$ values of the intercoder agreement were, although sufficient, not strong. One reason for the low Cohen $\kappa$ scores is that usability problems were often ambiguously formulated. Although we excluded many of these problems beforehand, during coding it became notable that the researchers had different opinions about the origins of some problems. This is not completely avoidable in qualitative research but does highlight the common problem in usability evaluation studies: the evaluator effect [59]. The usability researcher has a large influence on the output of usability evaluation studies (and thus the formulation of usability problems). A means to establish a more uniform approach for formulating usability problems was provided by Khajouei et al [60]. It describes a framework for high-quality reporting of usability problems that mentions the underlying causes, severity, and impact on task performance. Furthermore, the use of a standardized framework for coding usability problems can provide support against the evaluator effect, as it helps create a common ground between researchers.

\section{Conclusions}

The current set of usability benchmarking instruments only provides a limited overview of the usability of eHealth applications, as they do not consider eHealth-specific factors. Our reconceptualization of usability in the eHealth context will help practitioners and researchers better understand the usability problems they encounter in their evaluations and develop suitable benchmarking tools.

\section{Conflicts of Interest}

None declared.

\section{References}

1. Poppe L, Van der Mispel C, De Bourdeaudhuij I, Verloigne M, Shadid S, Crombez G. Users' thoughts and opinions about a self-regulation-based eHealth intervention targeting physical activity and the intake of fruit and vegetables: a qualitative study. PLoS One 2017 Dec 21;12(12):e0190020 [FREE Full text] [doi: 10.1371/journal.pone.0190020] [Medline: 29267396]

2. Canter KS, Deatrick JA, Hilgart MM, Myers J, Vega G, Ritterband LM, et al. eSCCIP: A psychosocial ehealth intervention for parents of children with cancer. Clin Pract Pediatr Psychol 2019 Mar;7(1):44-56. [doi: 10.1037/cpp0000264]

3. Stinson JN, Petroz GC, Tait G, Feldman BM, Streiner D, McGrath PJ, et al. e-Ouch: usability testing of an electronic chronic pain diary for adolescents with arthritis. Clin J Pain 2006;22(3):295-305. [doi: 10.1097/01.ajp.0000173371.54579.31] [Medline: 16514331]

4. van Velsen L, Evers M, Bara C, den Akker OH, Boerema S, Hermens H. Understanding the acceptance of an eHealth technology in the early stages of development: an end-user walkthrough approach and two case studies. JMIR Form Res 2018 Jun 15;2(1):e10474 [FREE Full text] [doi: 10.2196/10474] [Medline: 30684434] 
5. Walsh L, Hemsley B, Allan M, Adams N, Balandin S, Georgiou A, et al. The e-health literacy demands of Australia's my health record: a heuristic evaluation of usability. Perspect Health Inf Manag 2017;14(Fall):1f [FREE Full text] [Medline: 29118683]

6. Georgsson M, Staggers N. Quantifying usability: an evaluation of a diabetes mHealth system on effectiveness, efficiency, and satisfaction metrics with associated user characteristics. J Am Med Inform Assoc 2016 Jan;23(1):5-11 [FREE Full text] [doi: 10.1093/jamia/ocv099] [Medline: 26377990]

7. Peute LW, Spithoven R, Bakker PJ, Jaspers MW. Usability studies on interactive health information systems; where do we stand? Stud Health Technol Inform 2008;136:327-332. [Medline: 18487752]

8. Lewis JR. Psychometric evaluation of the post-study system usability questionnaire: the PSSUQ. In: Proceedings of the Human Factors Society 36th Annual Meeting. 1992 Presented at: HFES Annual - The Human Factors Society Annual Meeting; 1992; Atlanta, GA, USA p. 1259-1263.

9. Chin J, Diehl V, Norman K. Development of an instrument measuring user satisfaction of the human-computer interface. In: Proceedings of the SIGCHI Conference on Human Factors in Computing Systems. 1988 Presented at: CHI88: Human Factors in Computing Systems; May 15 - 19, 1988; Washington D.C. USA p. 213-218. [doi: 10.1145/57167.57203]

10. Brooke J. SUS: A 'Quick and Dirty' usability scale. In: Usability Evaluation In Industry. Boca Raton, Florida, United States: CRC Press; 1996:194.

11. Yen PY, Wantland D, Bakken S. Development of a customizable health IT usability evaluation scale. AMIA Annu Symp Proc 2010 Nov 13;2010:917-921 [FREE Full text] [Medline: 21347112]

12. Zhou L, Bao J, Setiawan IM, Saptono A, Parmanto B. The mHealth App Usability Questionnaire (MAUQ): development and validation study. JMIR Mhealth Uhealth 2019 Apr 11;7(4):e11500 [FREE Full text] [doi: 10.2196/11500] [Medline: $\underline{30973342]}$

13. Maramba I, Chatterjee A, Newman C. Methods of usability testing in the development of eHealth applications: a scoping review. Int J Med Inform 2019 Jun;126:95-104. [doi: 10.1016/j.ijmedinf.2019.03.018] [Medline: $\underline{31029270]}$

14. Broekhuis M, van Velsen L, Hermens H. Assessing usability of eHealth technology: a comparison of usability benchmarking instruments. Int J Med Inform 2019 Aug;128:24-31. [doi: 10.1016/j.ijmedinf.2019.05.001] [Medline: $\underline{31160008]}$

15. Ergonomics of human-system interaction — Part 11: Usability: definitions and concepts. International Organisation for Standardisation (ISO). 2018. URL: https://www.iso.org/obp/ui/\#iso:std:iso:9241:-11:ed-2:v1:en [accessed 2021-07-07]

16. Linek S, Tochtermann K. Assessment of usability benchmarks: combining standardized scales with specific questions. In: Proceedings of the 14th International Conference on Interactive Collaborative Learning. 2011 Presented at: 14th International Conference on Interactive Collaborative Learning; Sept. 21-23, 2011; Piestany, Slovakia p. 67-75. [doi: 10.1109/icl.2011.6059549]

17. Borsci S, Federici S, Malizia A, De Filippis ML. Shaking the usability tree: why usability is not a dead end, and a constructive way forward. Behav Inf Technol 2018 Nov 02;38(5):519-532. [doi: 10.1080/0144929x.2018.1541255]

18. Kim H, Xie B. Health literacy in the eHealth era: a systematic review of the literature. Patient Educ Couns 2017 Jun;100(6):1073-1082. [doi: 10.1016/j.pec.2017.01.015] [Medline: 28174067]

19. Hoogendam YY, van der Lijn F, Vernooij MW, Hofman A, Niessen WJ, van der Lugt A, et al. Older age relates to worsening of fine motor skills: a population-based study of middle-aged and elderly persons. Front Aging Neurosci 2014 Sep 25;6:259 [FREE Full text] [doi: 10.3389/fnagi.2014.00259] [Medline: 25309436]

20. Flores E, Tobon G, Cavallaro E, Cavallaro F, Perry J, Keller T. Improving patient motivation in game development for motor deficit rehabilitation. In: Proceedings of the 2008 International Conference on Advances in Computer Entertainment Technology. 2008 Presented at: ACE2008: International Conference in Advances in Computer Entertainment Technology; December 3-5, 2008; Yokohama Japan p. 381-384. [doi: 10.1145/1501750.1501839]

21. van Velsen L, Broekhuis M, Jansen-Kosterink S, den Akker HO. Tailoring persuasive electronic health strategies for older adults on the basis of personal motivation: web-based survey study. J Med Internet Res 2019 Sep 06;21(9):11759 [FREE Full text] [doi: 10.2196/11759] [Medline: $\underline{\text { 31493323] }}$

22. Abran A, Khelifi A, Suryn W, Seffah A. Consolidating the ISO usability models. In: Proceedings of the 11th International Software Quality Management Conference and the 8th Annual INSPIRE Conference. 2014 Presented at: 11th International Software Quality Management Conference and the 8th Annual INSPIRE Conference; June 16-20, 2014; Aalborg Denmark URL: http://citeseerx.ist.psu.edu/viewdoc/versions?doi=10.1.1.93.3969

23. Hasan L, Al-Sarayreh K. An integrated measurement model for evaluating usability attributes. In: Proceedings of the International Conference on Intelligent Information Processing, Security and Advanced Communication. 2015 Presented at: IPAC '15: International Conference on Intelligent Information Processing, Security and Advanced Communication; November 23 - 25, 2015; Batna Algeria p. 1-6. [doi: 10.1145/2816839.2816861]

24. Zhang D, Adipat B. Challenges, methodologies, and issues in the usability testing of mobile applications. Int J Hum Comput Interact 2005 Jul;18(3):293-308. [doi: 10.1207/s15327590ijhc1803_3]

25. Seffah A, Donyaee M, Kline RB, Padda HK. Usability measurement and metrics: a consolidated model. Software Qual J 2006 Jun;14(2):159-178. [doi: 10.1007/s11219-006-7600-8] 
26. van Welie M, van der Veer GC, Eliëns AP. Breaking down usability. In: Proceedings of Interact 99 - Human Computer Interaction. 1999 Presented at: Human Computer Interaction - Interact 99; August 30 - September 3, 1999; Edinburgh, Scotland p. 613-620 URL: https://research.vu.nl/en/publications/breaking-down-usability

27. Folmer E, Bosch J. Architecting for usability: a survey. J Sys Soft 2004 Feb;70(1-2):61-78. [doi: 10.1016/s0164-1212(02)00159-0]

28. Sardi L, Idri A, Fernández-Alemán JL. A systematic review of gamification in e-Health. J Biomed Inform 2017 Jul;71:31-48 [FREE Full text] [doi: 10.1016/j.jbi.2017.05.011] [Medline: 28536062]

29. Cabrita M, Tabak M, Vollenbroek-Hutten M. Mobile technology to monitor physical activity and wellbeing in daily life objective and subjective experiences of older adults. In: Proceedings of the 3rd International Conference on Information and Communication Technologies for Ageing Well and e-Health - ICT4AWE. 2017 Presented at: 3rd International Conference on Information and Communication Technologies for Ageing Well and e-Health - ICT4AWE; April 28-29, 2017; Porto, Portugal p. 164-171. [doi: 10.5220/0006321101640171]

30. Or C, Tao D. Usability study of a computer-based self-management system for older adults with chronic diseases. JMIR Res Protoc 2012 Nov 08;1(2):e13 [FREE Full text] [doi: 10.2196/resprot.2184] [Medline: 23612015]

31. Mackey LM, Doody C, Werner EL, Fullen B. Self-management skills in chronic disease management. Med Decis Making 2016 Apr 06;36(6):741-759. [doi: 10.1177/0272989x16638330]

32. Ash JS, Berg M, Coiera E. Some unintended consequences of information technology in health care: the nature of patient care information system-related errors. J Am Med Inform Assoc 2004;11(2):104-112 [FREE Full text] [doi: 10.1197/jamia.M1471] [Medline: 14633936]

33. Keizer R, van Velsen L, Moncharmont M, Riche B, Ammour N, Signore S, et al. Using socially assistive robots for monitoring and preventing frailty among older adults: a study on usability and user experience challenges. Health Technol 2019 Apr 9;9(4):595-605. [doi: 10.1007/s12553-019-00320-9]

34. Simon AC, Holleman F, Gude WT, Hoekstra JB, Peute LW, Jaspers MW, et al. Safety and usability evaluation of a web-based insulin self-titration system for patients with type 2 diabetes mellitus. Artif Intell Med 2013 Sep;59(1):23-31. [doi: 10.1016/j.artmed.2013.04.009] [Medline: 23735522]

35. Wildenbos G, Jaspers M, Schijven M, Dusseljee-Peute LW. Mobile health for older adult patients: using an aging barriers framework to classify usability problems. Int J Med Inform 2019 Apr;124:68-77. [doi: 10.1016/j.ijmedinf.2019.01.006] [Medline: 30784429]

36. Duh H, Tan G, Chen V. Usability evaluation for mobile device: a comparison of laboratory and field tests. In: Proceedings of the 8th Conference on Human-Computer Interaction with Mobile Devices and Services. 2006 Presented at: MobileHCI06: Human-Computer Interaction with Mobile Devices and Services; September 12 - 15, 2006; Helsinki Finland p. 181-186. [doi: $10.1145 / 1152215.1152254]$

37. Fried LP, Tangen CM, Walston J, Newman AB, Hirsch C, Gottdiener J, Cardiovascular Health Study Collaborative Research Group. Frailty in older adults: evidence for a phenotype. J Gerontol A Biol Sci Med Sci 2001 Mar 01;56(3):146-156. [doi: 10.1093/gerona/56.3.m146] [Medline: 11253156$]$

38. Bengtsson M. How to plan and perform a qualitative study using content analysis. NursingPlus Open 2016;2:8-14. [doi: 10.1016/j.npls.2016.01.001]

39. de Vet HC, Mokkink LB, Terwee CB, Hoekstra OS, Knol DL. Clinicians are right not to like Cohen's $\kappa$. Br Med J 2013 Apr 12;346:f2125. [doi: 10.1136/bmj.f2125] [Medline: 23585065]

40. Strijbos J, Martens RL, Prins FJ, Jochems WM. Content analysis: what are they talking about? Comput Educ 2006 Jan;46(1):29-48. [doi: 10.1016/j.compedu.2005.04.002]

41. Byrt T. How good is that agreement? Epidemiology 1996 Sep;7(5):561. [doi: 10.1097/00001648-199609000-00030] [Medline: $\underline{8862998]}$

42. Goodhue DL, Thompson RL. Task-technology fit and individual performance. MIS Q 1995 Jun;19(2):213. [doi: $10.2307 / 249689]$

43. Iwarsson S, Ståhl A. Accessibility, usability and universal design--positioning and definition of concepts describing person-environment relationships. Disabil Rehabil 2003 Jan 21;25(2):57-66. [doi: 10.1080/dre.25.2.57.66] [Medline: $\underline{12554380]}$

44. Queirós A, Silva A, Alvarelhão J, Rocha NP, Teixeira A. Usability, accessibility and ambient-assisted living: a systematic literature review. Univ Access Inf Soc 2013 Oct 5;14(1):57-66. [doi: 10.1007/s10209-013-0328-x]

45. Stephanidis C, Savidis A. Universal access in the information society: methods, tools, and interaction technologies. Univers Access Inf Soc 2001 Jun;1(1):40-55. [doi: 10.1007/s102090100008]

46. Newell A, Gregor P. "User sensitive inclusive design” — in search of a new paradigm. In: Proceedings on the 2000 Conference on Universal Usability. 2000 Presented at: CUU00: ACM Conference on Universal Usability; November 16 - 17, 2000 ; Arlington Virginia USA p. 39-44. [doi: 10.1145/355460.355470]

47. Fang X, Holsapple CW. An empirical study of web site navigation structures' impacts on web site usability. Decis Support Syst 2007 Mar;43(2):476-491. [doi: 10.1016/j.dss.2006.11.004]

48. Nielsen J. The usability engineering life cycle. IEEE Compu 1992 Mar;25(3):12-22. [doi: 10.1109/2.121503] 
49. Nielsen J. Usability metrics: tracking interface improvements. IEEE Softw 1996 Nov;13(6):1-2. [doi: $10.1109 / \mathrm{ms} .1996 .8740869]$

50. Farkas DK. Procedural and declarative information in software manuals: effects of information use, task performance, and knowledge. J Busi Tech Commun 2016 Jul 25;11(4):502-505. [doi: 10.1177/1050651997011004008]

51. Nielsen J. 10 usability heuristics for user interface design. Nielsen Norman Group. 1994. URL: https://www.nngroup.com/ articles/ten-usability-heuristics/ [accessed 2021-07-07]

52. Shackel B. The concept of usability. In: Bennett J, Case D, Sandelin J, Smith M, editors. Visual Display Terminals. Hoboken, New Jersey, United States: Prentice-Hall; 1984:45-88.

53. Voncken-Brewster V, Moser A, van der Weijden T, Nagykaldi Z, de Vries H, Tange H. Usability evaluation of an online, tailored self-management intervention for chronic obstructive pulmonary disease patients incorporating behavior change techniques. JMIR Res Protoc 2013 Jan 16;2(1):e3 [FREE Full text] [doi: 10.2196/resprot.2246] [Medline: 23612363]

54. Mirkovic J, Kaufman DR, Ruland CM. Supporting cancer patients in illness management: usability evaluation of a mobile app. JMIR Mhealth Uhealth 2014 Aug 13;2(3):e33 [FREE Full text] [doi: 10.2196/mhealth.3359] [Medline: 25119490]

55. Stinson J, McGrath P, Hodnett E, Feldman B, Duffy C, Huber A, et al. Usability testing of an online self-management program for adolescents with juvenile idiopathic arthritis. J Med Internet Res 2010 Jul 29;12(3):e30 [FREE Full text] [doi: 10.2196/jmir.1349] [Medline: 20675293]

56. Hattink B, Droes R, Sikkes S, Oostra E, Lemstra AW. Evaluation of the Digital Alzheimer Center: Testing usability and usefulness of an online portal for patients with dementia and their carers. JMIR Res Protoc 2016 Jul 21;5(3):e144 [FREE Full text] [doi: 10.2196/resprot.5040] [Medline: 27444209]

57. Baumel A, Muench F. Heuristic evaluation of eHealth interventions: establishing standards that relate to the therapeutic process perspective. JMIR Ment Health 2016 Jan 13;3(1):e5 [FREE Full text] [doi: 10.2196/mental.4563] [Medline: 26764209]

58. Elling S, Lentz L, de Jong M. Website Evaluation Questionnaire: Development of a Research-Based Tool for Evaluating Informational Websites. In: Electronic Government. Berlin: Springer; 2007:293-304.

59. Hertzum M, Jacobsen NE. The evaluator effect: a chilling fact about usability evaluation methods. Int J Hum-Comput Int 2003 Feb;15(1):183-204. [doi: 10.1207/s15327590ijhc1501 14]

60. Khajouei R, Peute L, Hasman A, Jaspers M. Classification and prioritization of usability problems using an augmented classification scheme. J Biomed Inform 2011 Dec;44(6):948-957 [FREE Full text] [doi: 10.1016/j.jbi.2011.07.002] [Medline: $\underline{21782036}$ ]

\section{Abbreviations}

GUI: general user interface

Health-ITUES: Health Information Technology Usability Evaluation Scale

ISO: International Organization for Standardization

MAUQ: Mental Health App Usability Questionnaire

PSSUQ: Poststudy System Usability Questionnaire

SUS: system usability scale

Edited by G Eysenbach; submitted 11.02.20; peer-reviewed by J Kimmerle, CH Chang, A Coe, H Witteman; comments to author 29.06.20; revised version received 02.09.20; accepted 31.05.21; published 27.07.21

Please cite as:

Broekhuis $M$, van Velsen L, Peute L, Halim M, Hermens $H$

Conceptualizing Usability for the eHealth Context: Content Analysis of Usability Problems of eHealth Applications JMIR Form Res 2021;5(7):e18198

URL: https://formative.jmir.org/2021/7/e18198

doi: $\underline{10.2196 / 18198}$

PMID: 34313594

CMarijke Broekhuis, Lex van Velsen, Linda Peute, Meilani Halim, Hermie Hermens. Originally published in JMIR Formative Research (https://formative.jmir.org), 27.07.2021. This is an open-access article distributed under the terms of the Creative Commons Attribution License (https://creativecommons.org/licenses/by/4.0/), which permits unrestricted use, distribution, and reproduction in any medium, provided the original work, first published in JMIR Formative Research, is properly cited. The complete bibliographic information, a link to the original publication on https://formative.jmir.org, as well as this copyright and license information must be included. 